\title{
Development of Electrochemical Impedance Immunosensor for Sensitive Determination of Myoglobin
}

\author{
Xianhui Ren ${ }^{1}$, Yang Zhang ${ }^{1}$, Yuqi Sun ${ }^{1}$ and Lili Gao ${ }^{2, *}$ \\ ${ }^{1}$ The Second Affiliated Hospital to Mudanjiang Medical University, Mudanjiang, P.R. China \\ ${ }^{2}$ Department of Clinical Laboratory, Hongqi Hospital, Mudanjiang Medical University, Aimin \\ District, Mudanjiang 157011, China. \\ *E-mail: liligao_mmu@yeah.net
}

doi: $10.20964 / 2017.08 .18$

Received: 9 February 2017 / Accepted: 25 May 2017 / Published: 12 July 2017

\begin{abstract}
Effective bio-recognition element immobilization on the surface of the transducer is significantly important for fabricating an immunosensor. Pithophora. Oedogonia, a green algae, has been employed as the reducing agent in this study to accomplish the biosynthesis of Au nanoparticles. The whole procedure of synthesis occurred rapidly where Au nanoparticles were produced within $1 \mathrm{~h}$ after the reaction between $\mathrm{Au}$ salt and algal extract. Subsequently, electrochemical impedance myoglobin immunosensor was constructed using the obtained AuNPs. A wide detection range can be achieved from 0.02 to $1 \mu \mathrm{M}$ either in phosphate buffered saline or the whole serum, Furthermore, the asfabricated immunosensors is potential to be utilised for the detection of myoglobin.
\end{abstract}

Keywords: Pithophora. oedogonia; Electrochemical impedance immunodetection; Myoglobin; Indium-tin-oxide; Acute myocardial infarction

\section{FULL TEXT}

(C) 2017 The Authors. Published by ESG (www.electrochemsci.org). This article is an open access article distributed under the terms and conditions of the Creative Commons Attribution license (http://creativecommons.org/licenses/by/4.0/). 